\title{
The Feasibility of Adopting an Evidence-Informed Tailored Exercise Program within Adult Day Services: The Enhance Mobility Program
}

Diane K. King, Sherilyn A. Faulkner \& Bridget L. Hanson

To cite this article: Diane K. King, Sherilyn A. Faulkner \& Bridget L. Hanson (2018) The Feasibility of Adopting an Evidence-Informed Tailored Exercise Program within Adult Day Services: The Enhance Mobility Program, Activities, Adaptation \& Aging, 42:2, 104-123, DOI: 10.1080/01924788.2017.1391030

To link to this article: https://doi.org/10.1080/01924788.2017.1391030

曲 Published online: 29 Nov 2017.

Submit your article to this journal $\sqsubset$

山 Article views: 249

View related articles

View Crossmark data $₫$ 


\title{
The Feasibility of Adopting an Evidence-Informed Tailored Exercise Program within Adult Day Services: The Enhance Mobility Program
}

\author{
Diane K. King, Sherilyn A. Faulkner, and Bridget L. Hanson \\ Center for Behavioral Health Research \& Services, Institute of Social and Economic Research, University \\ of Alaska Anchorage, Anchorage, AK, USA
}

\begin{abstract}
This article uses the RE-AIM framework to evaluate the feasibility of implementing Enhance Mobility (EM), a tailored, evidence-informed group exercise and walking program for older adults with dementia, into an adult day services center. Participant physical performance outcomes were measured at baseline and 8 months. Program staff were interviewed to understand implementation challenges. Participant outcomes did not change significantly, though gait speed improved from limited to community ambulation levels. Implementation challenges included space reallocation and adequate staffing. Adopting EM in adult day services is feasible, and has potential to reach older adults who could benefit from tailored exercise.
\end{abstract}

\section{ARTICLE HISTORY}

Received 12 July 2016

Accepted 17 April 2017

\section{KEYWORDS}

Adult day care; aging; Alzheimer's disease; community-based; dementia; developmental disabilities; exercise; mobility; physical activity; walking

Older adults with dementia and other cognitive limitations can benefit from exercise interventions that address predictors of premature institutionalization, such as falls risk, functional mobility, negative behaviors, depression, and caregiver burden (Desai \& Grossberg, 2001; Gaugler, Yu, Krichbaum, \& Wyman, 2009; Yaffe et al., 2002). Opportunities to exercise may be limited for community-dwelling adults with dementia who require assistance and tailoring of exercises to assure that they are performed in a safe and effective manner. Adult day programs provide an excellent setting for reaching older adults with dementia who could benefit from tailored exercise interventions; however, the capacity of these organizations to commit the resources and staff time necessary to adapt, integrate, and sustain a tailored physical activity program for their clients is understudied.

With more than $70 \%$ of Americans with Alzheimer's disease and other forms of dementia living at home or in the community (Alzheimer's Association, 2015), the need for effective, affordable, and convenient programming that addresses factors associated with institutionalization is increasing (Black et al., 2013; Cassie \& Sanders, 2008; Ivey et al., 2013). Adult day services are a rapidly growing alternative to institutional care 
with potential to provide personalized support to adults with dementia and their caregivers, forestalling the need for skilled nursing care (Kelly, Puurveen, \& Gill, 2014; MetLife Mature Market Institute, 2010). While such programs are diverse with regard to models of care, funding sources, staff credentials, services provided, and client needs, their potential to offer evidence-based, targeted programming that addresses critical physical and mental health factors is largely untapped (Logsdon, Pike, Korte, \& Goehring, 2014). The potential for adult day services to provide respite for caregivers and partially fulfill long-term care needs makes them an affordable alternative to home health aides, assisted living, or skilled nursing care (MetLife Mature Market Institute, 2012).

Exercise interventions for persons with dementia have demonstrated significant physiological benefits, including improvements in mood, functional mobility, and factors associated with fall prevention, such as improved gait speed, strength and balance (Taylor, Delbaere, Close, \& Lord, 2012; Teri, Logsdon, \& McCurry, 2008). Studies of adults with mild to moderate dementia show reductions in depression and improved physical functioning after just 60 minutes/week of exercise (Teri et al., 2003). For this reason, the Alzheimer's association campaign for quality care recommends the inclusion of movement and physical activity in care plans at home and within assisted living residences and nursing homes (Alzheimer's Association, 2009b; Alzheimer's Association, 2009a).

Group exercise programs are offered in about $80 \%$ of adult day services (MetLife Mature Market Institute, 2010); however, the extent that these programs have been demonstrated to be effective for persons with dementia is unknown. In addition, the literature rarely reports on the variety of factors affecting exercise program choice and delivery in adult day centers, such as constraints related to space, staffing, and the skills or opinions of program staff. Staff may be reluctant to encourage engagement in exercise for a variety of reasons, including their own fear that clients may be injured as well as their perception of clients' anxiety or agitation (Galik, Resnick, \& Pretzer-Aboff, 2009). Findings from research with geriatric nursing assistants working with nursing home residents with dementia reported that knowing the individual's past, using humor and play, offering favorite foods, and providing short verbal cues and repetition, were effective strategies for motivating clients to engage in physical activity and walking (Galik et al., 2009). Flexible scheduling of activities (Galik et al., 2009), consistency in staffing and space configuration, and supervision for clients to go at their own pace, are critical to maximizing engagement and program success (NICE Clinical Guidelines, 2007). Thus, given what we do know about potential staff challenges and client needs for individualized accommodation, identifying an evidence-based physical activity program that is suitable for adult day services clients as well as feasible for staff to deliver is challenging, particularly given the heterogeneity of 
adult day services philosophies, competing demands, staffing limitations, and client safety concerns (Luppa, Luck, Brahler, Konig, \& Riedel-Heller, 2008).

This study used mixed methods and the comprehensive RE-AIM (reach, effectiveness, adoption, implementation, and maintenance) framework (Klesges, Estabrooks, Glasgow, \& Dzewaltowski, 2005) to study the reach, effectiveness and feasibility of implementing Enhance Mobility (EM), an evidence-informed tailored group exercise and walking program. The implementation setting was an adult day services program for diverse clients with dementia and other cognitive disabilities. Our primary objectives in this article are to (1) describe the reach and effectiveness on participant quality of life (QOL) and physical performance outcomes, (2) present program staff perspectives obtained from key informant interviews to describe challenges and adaptations made to enhance EM's feasibility and maintenance potential, and (3) share lessons and recommendations to enhance implementation of EM within adult day services programs.

\section{Methods}

\section{Intervention: $E M$}

EM is an evidence-informed, tailored group exercise program developed for adults with dementia attending adult day services programs. EM was developed at the University of Washington (UW) based on combining elements of two evidence-based exercise intervention programs that reflect social learning and gerontology theories, as well as an understanding of neuropsychological and behavioral changes that occur in people with dementia (Teri et al., 2008). The programs that form the basis of EM have demonstrated improvements in predictors of falls, mood, and physical function. In brief, the group program format, which includes trained instructors and a series of exercises appropriate for older adults, was adapted from EnhanceFitness (Belza et al., 2006), a group exercise program conducted in community settings that in a 6-month randomized trial demonstrated significant improvements in depression, general health perceptions, social functioning, pain, and fatigue $(p<.05)$ (Wallace et al., 1998). Subsequent studies of EnhanceFitness demonstrated significant improvements in gait speed, endurance, and upper body strength (Snyder \& Barkey, 2006). The training of EM leaders in how dementia impacts behavior and impairs day-to-day function and the focus on how to individually encourage and help clients with their exercises were adapted from reducing disability in Alzheimer's disease (RDAD; Teri et al., 2003), which trains caregivers to use exercise and problem-solving to assist their care recipients (Logsdon \& Teri, 2010). Outcomes from a randomized control trial demonstrated significant improvements in the 
RDAD group compared to a usual care control group after 3 months with regard to role limitations due to physical health problems and depression, with improvements sustained at 24 months. Drawing from these two programs, the EM program consists of exercises that promote flexibility, strength, endurance, and balance, and offers an instructor's manual and materials to assist program implementation. Prior to our study, EM had been implemented in six adult day services programs and in one residential care home, all located in Washington state. An evaluation of the latter program demonstrated improved functional ability and fewer behavioral problems among the participants (Logsdon, 2012).

The EM program includes two components: group exercise and walking. The group exercise portion of the program consists of at least three repetitions of 20 exercises and is approximately 30 minutes in duration. The walking portion of the EM program consists of at least 20 minutes of walking which can be broken into smaller increments as needed. Program developers recommend that EM be conducted at least 3 days/week.

\section{Participant characteristics}

Program participants included older adults with dementia or other cognitive or developmental disability who attended adult day services from May 2013 to January 2014 and agreed to participate in the EM study. Adult day services staff participants represented a mix of management, nursing, and general program staff with varying prior experience leading physical activity groups.

\section{Setting characteristics}

The setting for implementing EM was a nonprofit adult day services organization in Anchorage, Alaska, hereafter referred to as AK-ADS. AK-ADS serves approximately 50 community-dwelling older adults with cognitive and/or functional impairments related to developmental disabilities and/or dementia. AKADS's clients (referred to as "guests") are culturally and ethnically diverse, with approximately 15\% Alaska Native, 9\% African American, 7\% Asian, and 3\% Hispanic guests. AK-ADS employs approximately 15 staff representing a mix of clinical (MD, RN, and social work) and nonclinical (high-school diploma with varying levels of experience working with older adults) backgrounds. AK-ADS uses a person-centered model, offering multiple simultaneous activities throughout the day, including exercise, music, socializing, crafts, games, and walking. Its three large rooms are set up for specific activities, with a lunchroom that is equipped with a full kitchen and furnished with small lunchroom tables; an activity room that contains round tables for crafts and games; and a "parlor" with comfortably arranged living room furniture, intended to facilitate relaxation and conversation. There is also a small room where guests can sit quietly, 
with fewer distractions, and an outdoor garden of raised vegetable and herb gardens that are tended by staff and guests. Service utilization at AK-ADS varies by guest, ranging from a few visits per year to full-time attendance of five visits per week.

\section{Evaluation framework}

The RE-AIM framework was developed to guide evaluation of translation, implementation, and dissemination of evidence-based interventions in practice and community settings, in order to enhance their external validity (Bryant, Alpeter, \& Whitelaw, 2006; Klesges et al., 2005). The framework draws from diffusion of innovations theory (Rogers, 1995) and multilevel ecological models (Glanz \& Bishop, 2010; Green, Richard, \& Potvin, 1996) in that it considers the importance of contextual factors that influence translation of the evidencebase into practice (Glasgow, Vogt, \& Boles, 1999). The framework's five domains pay attention to individual (i.e., reach, effectiveness, and maintenance of the behavior change for at least 6 months) and setting-level factors (i.e., adoption, implementation, and maintenance, i.e., institutionalization, of the intervention) that are important for balancing fidelity and feasibility, and for encouraging maximum population impact (Glasgow et al., 1999). RE-AIM encourages the use of mixed methods to describe contextual factors relevant to participant and staff engagement, obstacles, and adaptations that may be generalizable and foster widespread dissemination of the intervention (Dzewaltowski, Estabrooks, Klesges, Bull, \& Glasgow, 2004).

\section{Measures}

A mix of qualitative and quantitative data was collected to report on the five RE-AIM domains. Qualitative data were obtained from participating AKADS staff using a semi-structured interview protocol that was developed by the research team with input from AK-ADS management. Questions included staff perceptions of guest acceptance and participation in EM, perceptions of EM's impact on guests, the fit of EM in AK-ADS's programming, and challenges/successes when conducting EM. Quantitative data included participant demographics, the mini-mental state examination (MMSE; Folstein, Folstein, \& McHugh, 1975), and a short physical performance battery, detailed below.

\section{Individual measures of reach and effectiveness}

Reach was calculated as the number and percentage of eligible older adults participating in $E M$ and their representativeness, along with qualitative themes related to engaging participants in the intervention, identified through staff key informant interviews. 
Effectiveness measures assessed participants' functional performance. A short physical performance battery (Guralnik et al., 1994) designed to assess balance, strength, and endurance was administered by a trained staff nurse and a researcher, which included chair stands and balance tests. Chair stand scores reflect the number of successful chair stands, up to five. To test balance, individuals attempted to hold four different standing positions for 10 seconds each (i.e., standing with feet shoulder width apart, standing with feet together, standing with the ball of one foot beside the heal of the other, and standing with one foot behind the other). Balance scores reflect the number of balance positions (out of the four) that were held for 10 seconds. Balance time was calculated as the average length of time participants balanced while attempting the four tests. Gait speed, an important predictor of health and functional ability (Studenski, 2009), was also examined using a 10 meter walk assessment (Fritz \& Lusardi, 2009). AK-ADS participants completed three timed trials of the 10 meter walk and an average time was calculated. To assess perceived physical health, a single question from the QOL-Alzheimer's disease scale (QOL-AD), i.e., "How do you feel about your physical health? Would you say your physical health is...", was rated by respondents on a scale of 1 (poor) to 4 (excellent; Logsdon, Gibbons, McCurry, \& Teri, 1999). Numerous studies have shown that a single health question is useful in understanding how patients with a variety of health conditions perceive their overall health status, and that measures of selfrated health can predict clinical outcomes and mortality (Erikesson, Undén, \& Elofsson, 2001; Fayers \& Sprangers, 2002; Ruthig, Hanson, Pedersen, Weber, \& Chipperfield, 2011). The QOL-AD scale has been validated for persons with mild to moderate AD (Logsdon et al., 1999; Logsdon, Gibbons, McCurry, \& Teri, 2002) as well as for persons with mild cognitive impairment (Tatsumi, Yammato, Nakaaki, Hadano, \& Narumoto, 2011) and demonstrates good internal and external reliability.

\section{Setting-level measures of adoption, implementation, and maintenance}

Adoption describes characteristics of the setting and program staff that are relevant to determining the representativeness of the adopting agency. Data were obtained directly from AK-ADS and through direct observation of the setting.

Implementation and maintenance reflect fidelity to evidence-based protocols (e.g., proportion of weeks that EM was delivered at least three times), and qualitative themes identified through staff key informant interviews, including staff attitude toward EM and operational challenges and solutions.

\section{Procedures}

AK-ADS guests and their primary guardians and caregivers were informed of the program and pilot study during an AK-ADS-scheduled event. Primary 
guardians and caregivers discussed the EM program and the pilot study. Several EM participants and guardians discussed consent and assent forms with researchers and made a decision about whether or not to participate in the study. AK-ADS guests and guardians who did not attend the event were mailed letters with information about the EM program, the study, and consent forms. If a guardian provided consent for a guest to participate in the study, AK-ADS staff obtained assent from guests. Six AK-ADS staff were trained in April 2013 to deliver EM by program developer, Dr. Rebecca Logsdon, and were observed and provided feedback and coaching throughout the pilot period by a research team member using a "fidelity checklist". All guests at AK-ADS were invited to participate in each EM session offered, but data were collected only on those guests where prior consent/assent had been obtained.

Participant demographic data were obtained through guardians and caregivers and AK-ADS staff. Participants completed the functional performance measures at baseline and at 8-month follow-up.

The functional performance measures were completed by the AK-ADS staff nurse with one assistant (a nursing student volunteer or researcher). For participants unable to complete any portion of the physical assessment (e.g., unable to walk unassisted, unable to understand the instructions, or the tester did not feel a test was safe for that particular participant), the physical assessment battery tests were rated as incomplete.

Interviews with five AK-ADS staff, representing the program director, nurse, and three nonclinical program staff positions, were conducted 12 months after the start of EM. All staff who were interviewed were involved in the program from the start. Interviews were conducted by a research team member who was not previously involved in the project with AK-ADS. Interviews were approximately 30 minutes in length and were audio-recorded and transcribed. All research policies and procedures were approved by the University of Alaska Anchorage's Institutional Review Board.

\section{Data analyses}

\section{Quantitative data analysis}

Quantitative tracking and participant data were maintained using IBM SPSS. Descriptive statistics were calculated for reach data. Given the small sample size, nonparametric tests were indicated for outcome analyses. Wilcoxon signed-rank tests were conducted to compare baseline to follow-up.

\section{Qualitative data analysis}

Key informant interviews were transcribed verbatim and analyzed by research staff using NVivo. Interviews were analyzed through conventional 
content analysis (Danilovich, Hughes, Corcos, Marquez, \& Eisenstein, 2016) for main themes within and across interview questions. Interview transcriptions were read and an initial list of themes was developed and confirmed with the research team. A researcher coded interviews according to the theme list, and a second researcher verified the codes. Discrepancies were discussed between the two researchers to reach consensus.

\section{Results}

\section{Reach of EM}

The research team was provided a list that included 49 AK-ADS guests who attended AK-ADS. Legal guardians were notified about EM and the planned pilot study, with assurance that refusal to participate in data collection would not affect guests' ability to participate in EM, whenever it was offered. Twenty-eight older adult participants (57.14\%) were consented through legal guardians and provided assent to participate in the pilot study. At 8month follow-up, 22 participants remained. Reasons for attrition were withdrawal from adult day services or absence due to vacation or medical issues. Of the 11 participants with dementia, only two had been diagnosed with AD and neither completed follow-up measures. Twenty participants (six with dementia) completed assessments at both time points. Table 1 summarizes descriptive characteristics of participants.

Participation in EM group exercises and walking varied. EM was offered 153 times; the total participation in the group exercises for individuals' ranged from 0 to 138 sessions $(M=50.72$; $\mathrm{SD}=45.91)$. Walking was offered 96 days; individuals' total participation in walking ranged from 0 to 76 days $(M=20.20$; $\mathrm{SD}=19.63$ ). Table 2 presents additional descriptive information regarding the extent that the study participants who completed baseline and 8-month followup measures participated in EM group exercises and/or walking on a cumulative and weekly basis. Participants who persisted through the 8-month follow-up did not differ significantly from those who did not persist on any demographic or performance measures at baseline. While not significant, the MMSE score for those who did not persist was lower than for those who persisted $(M=17.67, \mathrm{SD}=11.18$ vs. $M=20.50, \mathrm{SD}=9.21)$.

Guest acceptance of EM, as reported by staff key informants, was generally positive. During and after initial implementation, staff identified EM as a good fit with needs of AK-ADS clients. One respondent stated, "I think they [the EM exercises] are pretty well-designed for the type of people we have." Another respondent said, "It [EM] serves a purpose for this place because of the limited range of movements that people can do." On the other hand, recruiting guests daily to participate in EM was challenging given limited staff resources and time. Respondents explained that it can be difficult to get 
Table 1. Descriptive characteristics of participants.

\begin{tabular}{|c|c|c|c|c|}
\hline \multirow[b]{2}{*}{ Characteristic } & \multicolumn{2}{|c|}{$\begin{array}{l}\text { All participants at } \\
\text { baseline } \\
(n=28)\end{array}$} & \multicolumn{2}{|c|}{$\begin{array}{l}\text { Participants retained to follow-up } \\
\qquad(n=20)\end{array}$} \\
\hline & $M$ & SD & $M$ & SD \\
\hline \multicolumn{5}{|l|}{ Cognition } \\
\hline Mini Mental State Examination (MMSE) & 19.85 & 9.54 & 20.50 & 9.21 \\
\hline \multicolumn{5}{|l|}{ Demographics } \\
\hline \multirow[t]{2}{*}{ Age } & 73.75 & 13.82 & 71.29 & 12.43 \\
\hline & $n$ & $\%$ & $n$ & $\%$ \\
\hline \multicolumn{5}{|l|}{ Gender } \\
\hline Male & 9 & 32.14 & 7 & 35.00 \\
\hline Female & 19 & 67.86 & 13 & 65.00 \\
\hline \multicolumn{5}{|l|}{ Race/ethnicity $^{\mathrm{a}}$} \\
\hline White & 18 & 64.29 & 13 & 65.00 \\
\hline Alaska Native & 3 & 10.71 & 2 & 10.00 \\
\hline Black or African American & 2 & 7.14 & 2 & 10.00 \\
\hline Asian & 1 & 3.57 & 1 & 5.00 \\
\hline American Indian & 1 & 3.57 & 1 & 5.00 \\
\hline Native Hawaiian or other Pacific Islander & 1 & 3.57 & 1 & 5.00 \\
\hline Other & 3 & 10.71 & 1 & 5.00 \\
\hline \multicolumn{5}{|l|}{ Level of education } \\
\hline Less than high school & 7 & 25.00 & 6 & 30.00 \\
\hline High-school graduate & 9 & 32.14 & 6 & 30.00 \\
\hline Some college & 3 & 10.71 & 2 & 10.00 \\
\hline College degree & 3 & 10.71 & 2 & 10.00 \\
\hline Vocational/tech certificate & 2 & 7.14 & 1 & 5.00 \\
\hline Missing & 4 & 14.29 & 3 & 15.00 \\
\hline \multicolumn{5}{|l|}{ Marital status } \\
\hline Widowed & 14 & 50.00 & 8 & 40.00 \\
\hline Never married & 9 & 32.14 & 7 & 35.00 \\
\hline Divorced & 4 & 14.29 & 4 & 20.00 \\
\hline Married & 1 & 3.57 & 1 & 5.00 \\
\hline \multicolumn{5}{|l|}{ Participant diagnoses } \\
\hline Developmental disability & 10 & 35.71 & 9 & 55.00 \\
\hline Dementia & 9 & 32.14 & 6 & 30.00 \\
\hline Cerebral vascular accident (CVA) & 3 & 10.71 & 2 & 10.00 \\
\hline Mental illness & 3 & 10.71 & 2 & 10.00 \\
\hline Alzheimer's disease & 2 & 7.14 & 0 & 0.00 \\
\hline Traumatic brain injury & 1 & 3.6 & 0 & 0.00 \\
\hline
\end{tabular}

Note. ${ }^{a}$ More than one category could apply, so total will sum to greater than $100 \%$.

Table 2. Participation in EM exercises and walking during the 8-month study period $(n=20)$.

\begin{tabular}{lcrr}
\hline Activity & Range $^{\mathrm{a}}$ & \multicolumn{1}{c}{$M$} & \multicolumn{1}{c}{ SD } \\
\hline Total number of EM sessions attended (out of 153 sessions) & $0-138.00$ & 50.72 & 45.91 \\
Average weekly number of EM exercise sessions attended & $0-3.83$ & 1.54 & 1.22 \\
Total number of days walked & $0-76.00$ & 20.20 & 19.63 \\
Average minutes walked per day & $4.20-22.97$ & 12.37 & 4.80 \\
\hline
\end{tabular}

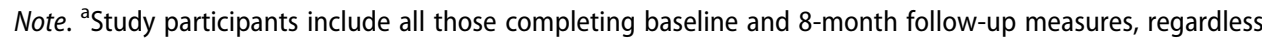
of whether they participated in EM sessions or walking. ${ }^{b}$ Only on days participating in program walking.

guests to stop playing cards or working on other activities to go to a different room for EM. One respondent indicated that recruiting guests for EM was different than recruiting for any other AK-ADS activity. Staff encouraged guests to participate by telling them that the activity is something they will 
enjoy, that it is good for them, that it will be fun, and that it is a social activity. One respondent said, "Just emphasizing it's not exercise. There's no jumping around or jumping jacks. It's just stretching. And it's fun."

Respondents reported that the social aspect of group exercise or walking drew people in to participate. When met with resistance from guests, some EM leaders said to guests, "You can just come and watch." Sometimes this approach would get guests to move into the EM room, and then they ended up doing some of the exercises when they saw that others were exercising too. Offering lemonade at the end of group exercise or walking was a simple yet successful way to motivate guests. For other difficult-to-reach guests, staff found phrasing the invitation similar to, "I could use your help" was useful for recruitment. One respondent summarized the various recruitment techniques, indicating "You have to find what works for them."

Maintaining guest engagement throughout the EM session so that they would get the full benefit was also identified as a challenge by staff. Several respondents reported that being silly and fun encouraged guests to have a good time during EM group exercise. One respondent described:

\begin{abstract}
Whenever we do the elbow....then we fly away and we row our boat. I have them imagine some place they've been that's beautiful and relaxing. And whenever they do the high knees at the end, I tell them we've been out clamming and we've got to get through the mud and the muck and the weeds, and you've got to have knees to get through it. Just making it fun and silly and trying to make them laugh if at all possible.
\end{abstract}

Accepting that not all guests will participate in EM when invited was also stressed as important to AK-ADS' person-centered approach to care. A few respondents discussed that the daily attempt to recruit guests, while time consuming, provided an opportunity to know who is tired or not feeling well, enabling them to better accommodate guests throughout the day. One respondent explained:

So if they didn't take part in it [EM], it didn't bother me. It's reported and then I would let other people know, well, she's really sleepy today or something like that. And then we would just watch the person a little bit more. So it gave us an opportunity to see everybody in the group and see how they are [feeling] on that particular day. So it gives you a real opportunity to just observe people and see how well they're doing.

Respondents also commented on how personalizing the EM exercises during the session to meet the needs of guests with varying physical and cognitive abilities created some challenges. For example, some guests do exercises sitting down, others do exercises standing up, occasionally making the groups difficult to manage and sometimes confusing for guests. EM leaders tried to encourage guests to participate in both group exercise and walking. 
Guests who used wheelchairs but were able to walk when supported were encouraged to get up and walk when they were supervised.

\section{Effectiveness of EM}

Inclusion criterion for effectiveness analyses was participation in more than one EM session. Based on this criterion, five study participants who did not participate in any EM sessions were excluded, leaving 15 eligible participants for effectiveness analyses. Wilcoxon signed-rank tests revealed no significant differences between baseline and 8-month follow-up on the physical activity tests and participants' self-rated health, see Table 3. Compared to baseline, at 8-month follow-up, there was no change in proportion of participants who could complete a chair stand unassisted and no change in participants' balance test scores. While not statistically significant, participants were able to balance for a longer period of time at follow-up. Participants' gait speed also improved from baseline to follow-up. While not statistically significant, the increase in speed represents a functional improvement from limited community ambulation to a gait speed considered sufficient for community ambulation (Fritz \& Lusardi, 2009; Levine, 2010). Participants' average selfrated health score diminished from baseline to follow-up, though not significantly and average health was rated "good" at both time points. While participants failed to show statistically significant improvement, given participants' age and health characteristics, the lack of decline is noteworthy.

In addition to the physical assessments, staff key informants also indicated observing success among guests, including physical and psychological improvements. Several respondents reported that a few guests who never did physical activity at AK-ADS before the start of EM now get

Table 3. Paired comparisons of physical abilities and health among EM participants attending more than one session $(n=15)$.

\begin{tabular}{|c|c|c|c|c|c|c|}
\hline Measure & Time $^{\mathrm{a}}$ & $M$ & SD & $n$ & $Z$ & $p^{\mathrm{b}}$ \\
\hline \multirow[t]{2}{*}{ Chair stands (number completed) } & 1 & 2.79 & 2.39 & 14 & 1.51 & .13 \\
\hline & 2 & 1.79 & 2.49 & & & \\
\hline \multirow[t]{2}{*}{ Balance (number completed out of four tests) } & 1 & 2.00 & 1.62 & 14 & 0.00 & 1.00 \\
\hline & 2 & 2.00 & 1.57 & & & \\
\hline \multirow[t]{2}{*}{ Balance time (seconds) } & 1 & 6.06 & 3.74 & 14 & 1.13 & .26 \\
\hline & 2 & 6.63 & 4.41 & & & \\
\hline \multirow{2}{*}{ Gait speed (seconds) ${ }^{c}$} & 1 & 14.20 & 19.29 & 13 & 1.29 & .20 \\
\hline & 2 & 12.29 & 13.76 & & & \\
\hline \multirow[t]{2}{*}{ Self-rated health ${ }^{d}$} & 1 & 3.31 & 0.48 & 13 & 1.10 & .27 \\
\hline & 2 & 2.92 & 0.95 & & & \\
\hline
\end{tabular}

Notes. ${ }^{\text {a Time }} 1$ represents baseline; Time 2 represents 8-month follow-up. ${ }^{\text {b}}$ To adjust for multiple comparisons, alpha $=.01$. 'Average 10-m walk time measured in seconds: $\leq 7=$ "normal" walking speed; $8-12.5=$ community ambulation; 12.5-25 = limited community ambulation (Fritz \& Lusardi, 2009; Levine, 2010). ${ }^{\mathrm{d} S}$ Scale of 1 (poor) to 4 (excellent). 
up and walk. Respondents also reported perceptions of improved guest balance, strength from sitting to standing, and stretching abilities. One respondent described a guest's experience with EM, saying, "[Guest] is just so much more stable and independent and in a better frame of mind... he has been able to do other programs with us. He dances better and some of our bowling and soccer and things like that, he is more capable of participating in."

Respondents attributed mobility improvements or retention of physical function to EM participation. One respondent stated:

We've got some people who are able to stand up better and some people have a little better balance. Some people just... through the progression of their disease, they have declined. But that's just the progression of their disease. It's not progressed as fast as it would have without Enhance Mobility.

Another respondent described the physical improvement by those participating in group exercise as a whole, "I've seen remarkable things that amaze me; like the whole class during a period where everybody did [the exercises] and did them perfectly."

Improvements in functional ability were attributed to EM participation by several respondents, who described how these improvements reduced work for AK-ADS staff and increased guest autonomy. For example, one staff member said, "I've seen people maintain their body strength for helping transfer themselves with another person from off their chair for toileting which is really a big deal." A few respondents mentioned several guests who had fallen less frequently since the start of the EM program. Another guest was described who can now do more tasks without assistance, "But you can tell [Guest] has improved because she is able to stand up easier. And she has been able to walk further, so it's just really encouraging. She can get her coat off and on easier. She doesn't need as much help."

Increased self-confidence, dignity, relaxation, focus, and improved mood were the most frequently staff-reported psychological improvements for guests participating in EM. A key informant discussed a guest who seemed to especially benefit from the walking program:

Just with [Guest] being able to walk, he is getting endorphins. Because earlier on in the day, I'll see him and he will have a lot of [distress] and will just work himself up and will do a lot of crying, but when he is walking, he is never crying.

Respondents reported that there was also an altruistic benefit for guests; several guests felt like they were helping others by being part of a university study. Respondents mentioned that guests enjoy helping others and EM provided a unique opportunity.

Ability to participate fully in EM is limited for some guests. Although key informants described several benefits to guests, one respondent described 
how guests with more severe cognitive limitations most likely obtained limited benefit from EM programming:

There are several [guests] that just cannot follow verbal or visual cues for more than maybe 10 or 15 seconds at a time, and they just cannot keep up...For the 20 to 25 minutes of the Enhance Mobility program exercise, they're reminded every 30 seconds to do this. It's too much stimulation for them. They will sit, but we'll usually put them in an outer circle, so they can participate as much as they want or watch as much as they want.

\section{Adoption of EM}

Setting and staff characteristics were described earlier. An important factor related to generalizability of EM to other settings was that staff with limited experience working in adult day services and little to no prior experience leading exercise programs, were trained to deliver EM with fidelity. Among the five staff interviewed, tenure ranged from 1.5 to 5.5 years $(M=3.4$ years). Two interviewees had experience leading the pre-EM exercise program, which was a non-tailored, standardized, audiotaped program set to music.

Staff key informants reflected that when EM was originally introduced to staff, a few staff members had expressed concerns about the new program. Specifically, one respondent had felt apprehensive about whether it would work well at AK-ADS since the guests were used to an exercise program that was familiar and set to music. While a decision was made to exchange EM for the old program, one staff reported discussing methods for "... phasing it in without causing too much anxiety or making anybody feel left out." On the other hand, several respondents reported that they were, from the beginning, excited about providing something new and more tailored than the previous exercise program.

\section{Implementation of EM}

During the 36 week pilot period, EM delivery ranged from 2 times to 5 times per week $(M=4.25$; SD $=0.92)$, and was offered at least 3 times most weeks $(94.44 \%)$.

Operational challenges related to implementing EM were discussed by respondents along with solutions that were adopted to enhance program feasibility and success. An unexpected early challenge was the identification and adaptation of the physical space where the EM exercises would be held. One respondent reflected, "...how do we organize that room such that we have these chairs to do it and bring the furniture back for other activities?"

While EM requires minimal equipment, chairs needed to be light enough to stack, sturdy with arm rests, and the right height for most guests to be able to put their feet on the floor. Staff spent significant time and resources 
finding the right chairs for EM group exercise. One respondent discussed searching for appropriate chairs, and said:

People needed to be able to sit toward the front of the chair, have their feet on the floor, have enough space for hands at the side, have arms so if they needed to push off. You would think it's not a big deal, but then you go look at the chairs we had in house and they didn't fit the bill... That was a bit of a challenge. It wasn't just run down to a store or open up a catalogue.

Staff narrowed the selections down to two or three chairs and tested them to make sure they were safe and appropriate.

Space needs for performing the exercises required some rearrangement of activities and furniture within the activity rooms. A few key informants reported challenges with the size of the facility and one respondent said, "You need a lot of space to do the exercises right; especially if everyone wants to go do them then you need a pretty big room." Another said, "It's not going to work, if you don't have enough room for it. It will just be frustrating if you do it in the wrong setting or in the wrong chairs. They need to be able to see the instructor. If they just line them up in a row, it's not going to work."

Staff time was another frequently identified challenge, given the need to personally recruit guests to participate in EM and to also assure the correct staff-to-guest ratios throughout the group exercise and walking portions of the program. Staff reported that a staff to guest ratio of 1:3 was ideal for group exercise, and 1:1 was ideal for walking for guests needed assistance. Staff recommended recruitment of volunteers to assist with the walking component of the program when possible, since more staff are required.

Respondents stated that it took an average of 10 minutes to recruit guests for group exercise and between 2 and 25 minutes per day to recruit guests for walking, depending on the day, who was attending, and how many walking sessions were facilitated. The EM walking component often required at least two staff members because guests walk at different speeds and cannot walk unattended. Interview respondents reported that staff time needed to be organized differently for the walking component, depending on the arrival and departure time of both staff members and guests. One solution AK-ADS found was to stagger walking with just a few guests at a time, and to also use volunteers for the walking component when they were available, thus reducing AK-ADS staff time needed.

Improved staff skills in tailoring EM exercises to participants, required some trial and error, and sharing of best practices among program leaders. Because each EM exercise is designed to be graded to each participant's ability, staff found it initially challenging to accommodate different levels of ability within a single group. For example, one section of EM includes sitting and standing versions of each exercise. Several leaders were not sure how to incorporate standing exercises at first. EM leaders watched each other lead the exercise 
program and talked through different potential approaches. EM leaders were able to incorporate the standing exercises for guests who were able by moving all of the standing exercises to the end of the program so guests only had to change positions once, and having guests stand behind their chairs. Exercise instructions were given for the sitting guests first, and then for the standing guests second. EM leaders worked to find the balance between challenging guests enough and not pushing them too hard. One respondent reported, "We learned from each other who could stand, which people couldn't, which people needed help."

\section{Maintenance of EM}

After 1 year of EM implementation, staff indicated that the program is a part of their routine. Staff described meaningful differences between their previous exercise program and EM. EM provided guests with step-by-step instructions for each movement, and the reason for each exercise. One staff member felt that EM is educational, in addition to an exercise program;

...what I liked about the Enhance Mobility program was that it was more specialized, and it more took [into consideration] the muscle movements. And it told them [guests] what they were doing, what parts of their body were being exercised.

So it became like a learning process for them.

After the conclusion of data collection with AK-ADS, management discussed plans to continue to use the EM fidelity checklist developed for the study as a way to coach new staff members. Experienced EM leaders will observe new leaders and use the checklist as a tool to discuss feedback about the exercises. This training plan demonstrates the ability of AK-ADS to sustain the program beyond the study period, without the assistance of research staff. In addition to monitoring new staff with an EM-specific fidelity form, the AK-ADS plans to continue collecting cognitive and physical assessments with guests.

\section{Discussion}

The number of older adults in need of services that support their ability to remain in their community is rapidly growing (McDonough \& Davitt, 2011). Adult day services programs are included by the National Alzheimer's Project Act (NAPA) as an important strategy for supporting the needs of persons with AD (United States Department of Health and Human Services, 2012). This article used mixed methods and RE-AIM to describe the reach and effectiveness of a tailored group exercise and walking program that was delivered within an adult day services center. Data collected included staff identified challenges and recommendations for improving the reach, 
feasibility, and potential for maintaining the program long term. The effort to integrate evidence-informed programs like EM into adult day services is important, given the potential of such settings to offer adults with AD exercise interventions that specifically target predictors of premature institutionalization (Teri et al., 2008). Tailored exercise interventions like EM are consistent with adult day services goals to provide safe, person-centered, and effective care (National Adult Day Services Association, 2011); however, changing or adopting new programming that requires staff training and time may be challenging.

Interviews with staff experienced with leading EM revealed themes and lessons associated with each of the five RE-AIM dimensions: guest acceptance and engagement, perceptions of program effectiveness, operational challenges and solutions, and program delivery challenges faced by staff when learning how to successfully deliver EM. While staff had some reasonable concerns before and early in the implementation process, they were able to incorporate EM into the regular routine, engage guests, and observe meaningful positive results. Accepting that not all guests would engage in or benefit from EM was consistent with AK-ADS' person-centered philosophy. Also, personalized recruitment using strategies consistent with what other dementia service providers use to encourage participation in physical activity and walking (Galik et al., 2009), and accommodation of guests with varying levels of physical and cognitive abilities, was considered valuable and recognized as important to maximizing EM's potential benefits. Accommodating guests with more severe cognitive impairment was identified as challenging, but staff willingness to share best practices and learn from observing each other was an important strategy. In addition, staff advice about configuring space in a way that provides adequate room for performing the exercises safely, and ensures visual contact with all participants throughout the session, is a program adoption challenge that has been identified in other studies of community-based group exercise (Belza et al., 2014). For example, interviews with Young Women's Christian Association (YWCA) staff discussed difficulty making room for programs that would compete with existing programs for limited space, and that ability to allocate space and time may predict organizational readiness to adopt (Klesges et al., 2005).

This paper used the RE-AIM framework and a mix of prospective, standardized, validated quantitative measures, and qualitative data collected from staff, so as to provide contextual information that would enhance the external validity of findings. While we conducted performance measures to objectively demonstrate program effectiveness in improving or retaining measureable physical mobility outcomes, a potential limitation of the study was our not including a measure of functional ability or falls that occurred at the setting. We instead relied on staff anecdotes about individual guests requiring less help with toileting, transferring, dressing, and 
fewer observed falls, which they attributed to participation in the group exercise and walking components of the EM program. In addition, given the small participant sample and single site description the participant outcomes and experiences of staff described here may not generalize to other adult day service centers, although the specific recommendations of staff are likely to be transportable.

Despite these limitations, this study demonstrates that it was effective and feasible to offer group exercise and walking interventions for a mixed population of older adults with dementia and other cognitive limitations within adult day services. Incorporating evidence-informed programming, such as $\mathrm{EM}$, in a way that maximizes its reach and effectiveness and addresses feasibility concerns is often a challenge for organizations facing staffing shortages and competing demands. Sharing real-world lessons and experiences from adult day services providers is useful to document both challenges and solutions that facilitated successful adoption and may contribute to establishing best practices for offering EM and other evidence-based activities that will promote the ability of persons with dementia and other cognitive disabilities to age safely within their community and reduce the costs of care. Areas for future research include continued EM implementation research in other adult day services settings, potential for partnering with volunteer programs to address feasibility concerns about offering more staff-intensive exercise and walking programming, and studying long-term outcomes for EM program participants with dementia and other developmental or cognitive conditions, in controlled trials.

\section{Acknowledgments}

The authors gratefully acknowledge the contributions of the Salvation Army of Alaska and Serendipity Adult Day Services, particularly Cathy Brenner, Jesalyn Stanton, Lori Stanton, and staff who worked hard to get the Enhance Mobility program running. The authors would also like to thank Rebecca Logsdon from the University of Washington for sharing the Enhance Mobility program and training Serendipity staff and researchers to conduct the program.

\section{Funding}

This work was supported by a grant from the Alaska Mental Health Trust Authority, grant no. 4743 .

\section{References}

Alzheimer's Association. (2009a). Dementia care practice recommendations for assisted living residences and nursing homes. Retrieved from https://www.alz.org/national/documents/ brochure_DCPRphases1n2.pdf 
Alzheimer's Association. (2009b). Dementia care practice recommendations for professionals working in a home setting. Retrieved from https://www.alz.org/national/documents/phase_ 4_home_care_recs.pdf

Alzheimer's Association. (2015). 2015 Alzheimer's disease facts and figures. Alzheimer's \& Dementia, 11, 332-384. doi:10.1016/j.jalz.2015.02.003

Belza, B., Petrescu-Prahova, M., Kohn, M., Miyawaka, C., Farren, L., Kline, G., \& Hilary-Heston, A. (2014). Adoption of evidence-based health promotion programs: Perspectives of early adopters of Enhance ${ }^{\circ}$ Fitness in YMCA-affiliated sites. Frontiers in Public Health, 2, 164.

Belza, B., Shumway-Cook, A., Phelan, E. A., Williams, B., Snyder, S. J., \& LoGerfo, J. P. (2006). The effects of a community-based exercise program on function and health in older adults: The EnhanceFitness Program. Journal of Applied Gerontology, 25, 291-306. doi:10.1177/0733464806290934

Black, B. S., Johnston, D., Rabins, P. V., Morrison, A., Lyketsos, C., \& Samus, Q. M. (2013). Unmet needs of community-residing persons with dementia and their informal caregivers: Findings from the maximizing independence at home study. Journal of the American Geriatrics Society, 61, 2087-2095. doi:10.1111/jgs.12549

Bryant, L. L., Alpeter, M., \& Whitelaw, N. A. (2006). Evaluation of health promotion programs for older adults: An introduction. Journal of Applied Gerontology, 25, 197-213. doi: $10.1177 / 0733464806288562$

Cassie, K., \& Sanders, S. (2008). Familial caregivers of older adults. In S. Cummings, \& N. Kropf (Eds.), Handbook of psychosocial interventions with older adults: Evidence-based approaches (pp. 293-320). Philadelphia, PA: Haworth Press.

Danilovich, M. K., Hughes, S. L., Corcos, D. M., Marquez, D. X., \& Eisenstein, A. R. (2016). Translating strong life into the community care program: Lessons learned. Journal of Applied Gerontology, Advance online publication. doi:10.1177/0733464815625833

Desai, A. K., \& Grossberg, G. T. (2001). Recognition and management of behavioral disturbances in dementia. Primary Care Companion to the Journal of Clinical Psychiatry, 3, 93-109. doi:10.4088/PCC.v03n0301

Dzewaltowski, D. A., Estabrooks, P. A., Klesges, L. M., Bull, S. S., \& Glasgow, R. E. (2004). Behavior change intervention research in community settings: How generalizable are the results? Health Promotion International, 19, 235-245. doi:10.1093/heapro/dah211

Erikesson, I., Undén, A., \& Elofsson, S. (2001). Self-rated health. Comparisons between three different measures. Results from a population study. International Journal of Epideliology, 30, 326-333. doi:10.1093/ije/30.2.326

Fayers, P. M., \& Sprangers, M. A. G. (2002). Understanding self-rated health. The Lancet, 359, 187-188. doi:10.1016/S0140-6736(02)07466-4

Folstein, M. F., Folstein, S. E., \& McHugh, P. R. (1975). Mini mental state: A practical method for grading the cognitive state of patients for the clinician. Journal of Psychiatric Research, 12, 189-198. doi:10.1016/0022-3956(75)90026-6

Fritz, S., \& Lusardi, M. (2009). White paper: Walking speed: The sixth vital sign. Journal of Geriatric Physical Therapy, 32, 2-5. doi:10.1519/00139143-200932020-00002

Galik, E. M., Resnick, B., \& Pretzer-Aboff, I. (2009). 'Knowing what makes them tick': Motivating cognitively impaired older adults to participate in restorative care. International Journal of Nursing Practice, 15, 48-55. doi:10.1111/ijn.2009.15.issue-1

Gaugler, J. E., Yu, F., Krichbaum, K., \& Wyman, J. F. (2009). Predictors of nursing home admission for persons with dementia. Medical Care, 47, 191-198. doi:10.1097/ MLR.0b013e31818457ce

Glanz, K., \& Bishop, D. B. (2010). The role of behavioral science theory in development and implementation of public health interventions. Annual Review of Public Health, 31, 399418. doi:10.1146/annurev.publhealth.012809.103604 
Glasgow, R. E., Vogt, T. M., \& Boles, S. M. (1999). Evaluating the public health impact of health promotion interventions: The RE-AIM framework. American Journal of Public Health, 89, 1922-1927. doi:10.2105/AJPH.89.9.1322

Green, L. W., Richard, L., \& Potvin, L. (1996). Ecological foundations of health promotion. American Journal of Health Promotion, 10, 270-281. doi:10.4278/0890-1171-10.4.270

Guralnik, J. M., Simonsick, E. M., Ferrucci, L., Glynn, R. J., Berkman, L. F., et al. (1994). A short physical performance battery assessing lower extremity function: Association with self-reported disability and prediction of mortality and nursing home admission. $J$ Gerontol, 49, M85-94.

Ivey, S. L., Laditka, S. B., Price, A. E., Tseng, W., Beard, R. L., Liu, R., ... Logsdon, R. G. (2013). Experiences and concerns of family caregivers providing support to people with dementia: A cross-cultural perspective. Dementia, 12, 806-820. doi:10.1177/ 1471301212446872

Kelly, R., Puurveen, G., \& Gill, R. (2014). The effect of adult day services on delay to institutional placement. Journal of Applied Gerontology, Advance online publication. doi:10.1177/0733464814521319

Klesges, L. M., Estabrooks, P. A., Glasgow, R. E., \& Dzewaltowski, D. (2005). Beginning with the application in mind: Designing and planning health behavior change interventions to enhance dissemination. Annals of Behavioral Medicine, 29, 66S-75S. doi:10.1207/ s15324796abm2902s_10

Levine, P. (2010). Using gait speed as a marker for progress. Advance for Physical Therapy \& Rehab Medicine, 21, 38.

Logsdon, R. G. (2012). Enhance Mobility: Boarding home pilot project. Unpublished report.

Logsdon, R. G., Gibbons, L. E., McCurry, S. M., \& Teri, L. (1999). Quality of life in Alzheimer's disease: Patient and caregiver reports. Journal of Mental Health and Aging, $5,21-32$.

Logsdon, R. G., Gibbons, L. E., McCurry, S. M., \& Teri, L. (2002). Assessing quality of life in older adults with cognitive impairment. Psychosomatic Medicine, 64, 510-519. doi:10.1097/ 00006842-200205000-00016

Logsdon, R. G., Pike, K. C., Korte, L., \& Goehring, C. (2014). Memory care and wellness services: Efficacy of specialized dementia care in adult day services. The Gerontologist, Advance online publication. doi:10.1093/geront/gnu012

Logsdon, R. G., \& Teri, L. (2010). An evidence-based exercise and behavior management program for dementia care. Generations, 34, 80-83.

Luppa, M., Luck, T., Brahler, E., Konig, H. H., \& Riedel-Heller, S. G. (2008). Prediction of institutionalisation in dementia: A systematic review. Dementia and Geriatric Cognitive Disorders, 26, 65-78. doi:10.1159/000144027

McDonough, K. E., \& Davitt, J. K. (2011). It takes a village: Community practice, social work, and aging-in-place. Journal of Gerontological Social Work, 54, 528-541. doi:10.1080/ 01634372.2011 .581744

MetLife Mature Market Institute. (2010). The MetLife national study of adult day services, 2010. Retrieved from https://www.metlife.com/assets/cao/mmi/publications/studies/2010/ mmi-adult-day-services.pdf

MetLife Mature Market Institute. (2012). Market survey of long-term care costs. Retrieved from: https://www.metlife.com/assets/cao/mmi/publications/studies/2012/studies/mmi2012-market-survey-long-term-care-costs.pdf

National Adult Day Services Association. (2011). National Adult Day Services Association research agenda. Retrieved from: http://nadsa.org/national-adult-day-services-associationresearch-agenda/ 
NICE Clinical Guidelines, No. 42. (2007). Dementia: A NICE-SCIE guideline on supporting people with dementia and their careers. In Health and Social Care, Chapter 7. National Collaborating Centre for Mental Health (UK). Leicester (UK): British Psychological Society.

Rogers, E. (1995). Diffusion of Innovations. New York, NY: Free Press.

Ruthig, J. C., Hanson, B. L., Pedersen, H., Weber, A., \& Chipperfield, J. G. (2011). Later life health optimism, pessimism, and realism: Psychosocial contributors and health correlates. Psychology and Health, 26, 835-853.

Snyder, S., \& Barkey, B. (2006). Enhancing fitness with EnhanceFitness. Retrieved from http://www.adph.org/alphtn/470handouts.pdf

Studenski, S. (2009). Bradypedia: Is gait speed ready for clinical use? The Journal of Nutrition, Health, and Aging, 13, 878-880. doi:10.1007/s12603-009-0245-0

Tatsumi, H., Yamamoto, M., Nakaaki, S., Hadano, K., \& Narumoto, J. (2011). Utility of the Quality-of-Life-Alzheimer's Disease Scale for mild cognitive impairment. Psychiatry and Clinical Neurosciences, 65, 533. doi:10.1111/pcn.2011.65.issue-5

Taylor, M. E., Delbaere, K., Close, J. C. T., \& Lord, S. R. (2012). Managing falls in older patients with cognitive impairment. Aging and Health, 8, 573-588. doi:10.2217/ahe.12.68

Teri, L., Gibbons, L. E., McCurry, S. M., Logsdon, R. G., Buchner, D. M., Barlow, W. E., ... Larson, E. B. (2003). Exercise plus behavioral management in patients with Alzheimer disease: A randomized controlled trial. The Journal of the American Medical Association, 290, 2015-2022. doi:10.1001/jama.290.15.2015

Teri, L., Logsdon, R. G., \& McCurry, S. M. (2008). Exercise interventions for dementia and cognitive impairment: The Seattle protocols. The Journal of Nutrition Health and Aging, 12, 391-394. doi:10.1007/BF02982672

United States Department of Health and Human Services. (2012). Obama administration presents national plan to fight Alzheimer's disease. Retrieved from http://www.nia.nih.gov/ newsroom/2012/05/obama-administration-presents-national-plan-fight-alzheimers-disease

Wallace, J. I., Buchner, D. M., Grothaus, L., Leveille, S., Tyll, L., LaCroix, A. Z., \& Wagner, E. H. (1998). Implementation and effectiveness of a community-based health promotion program for older adults. Journal of Gerontology: Medical Sciences, 53A, M301-M306.

Yaffe, K., Fox, P., Newcomer, R., Sands, L., Lindquist, K., Dane, K., \& Covinsky, K. E. (2002). Patient and caregiver characteristics and nursing home placement in patients with dementia. The Journal of the American Medical Association, 287, 2090-2097. doi:10.1001/ jama.287.16.2090 